\title{
Enigma de (Poe)sía: "El burro" de Roberto Bolaño y "Gas de los matrimonios" de Eduardo Espina
}

\author{
Dra. Mirian Pino*
}

\section{Resumen:}

El objetivo de este trabajo es realizar un primer acercamiento a la producción poética de Roberto Bolaño y Eduardo Espina. La perspectiva privilegia dos textos de ambos autores a través de los cuales es posible observar un diálogo con la tradición literaria y las formas de apropiación de las mismas. Los caminos adoptados por ellos, si bien son diferentes, instituyen un modo de asumir la creación literaria desde una particular percepción poética, situada más allá de las leyes del mercado.

Palabras clave: diálogo - tradición literaria - apropiación - creación literaria - mercado.

\section{Abstract:}

The aim of this article is to have a preliminary approach towards Roberto Bolaño and Eduardo Espina's poetical production. The writer's perspective emphasizes two works written by the two authors, through which it is possible to observe a dialogue with literary traditions and the forms in which they are internalized. The roads taken by the two literary pieces, however dissimilar, institutionalize a way of grasping literary creation from a particular poetical perspective that go beyond market regulations.

Key words: dialogue, literary tradition, internalization, literary creation, market.

* Argentina. Dra. en Literatura Latinoamericana. Universidad Nacional de Córdoba. Facultad de Letras.miriampino@fibertel.com.ar 


\section{Introducción}

En El origen y el sentido Ives Bonnefoy (2002) comenta al respecto de la relación entre poesía y sociedad, poesía y universidad que hay una zona de la primera inasible, una dimensión de aquella resistente a toda administración teórica; expresa a propósito de las teorías literarias en boga en Francia de los ochenta: "Por otra parte, será preciso que nos planteemos ahora una cuestión que no se le ocurrió a ningún exegeta, me parece, en los años recientes, demasiado intensamente fascinados por el álgebra y la geometría del lenguaje: la cuestión de saber si esa lectura "salvaje", ignorante de los semas y de los lexemas. Incluso a veces despreocupada del sentido epocal de las palabras, deber ser vista por nosotros, apasionados lectores de matices, a pesar de todo y en primer lugar como una ignorancia, una torpeza que hay que reparar poco a poco mediante la cultura y la ciencia, o si es todo lo contrario, en sus momentos de mayor ardor, el verdadero encuentro con el dato poético, la vía que el intelecto no sabe hallar, pero que no es por eso menos evidente, tal como la famosa "carta robada" que no era en el relato de Poe más que la designación simbólica (...)" (Bonnefoy: 78). Cercana a esta reflexión, Roberto Bolaño expresa asir la poesía "ya no como un cubículo universitario, ya no como un flujo circular de información, sino como una experiencia nueva del lenguaje, lenguaje vivo" (Bolaño: Plural). En esta dirección, me permito acceder al espacio poético con la plena consciencia del límite que implica encorsetar a la poesía de Roberto Bolaño y de Eduardo Espina en un registro duro, es decir, el de las clasificaciones.

Así, el objetivo de este estudio será abismarme en esas fronteras y bordear la crítica canónica con el fin de evitar el comentario panorámico. Evitarlo a través de la selección de dos muestras, "El burro" y "Gas de los matrimonios", extraídas de Los perros románticos (1998) de Roberto Bolaño y Mínimo de mundo visible (2003) ${ }^{1}$ de Eduardo Espina, respectivamente; por otra parte, es mi intensión hacer devenir esta reflexión en acto de fe que implica el placer del texto, placer basado en un a priori, en un principio situado más acá de la tekné o del discurso científico y que es relacionable a una existencia evidente: los lectores, la lectura, la comunión con la lectura y la escritura. Placer que me condujo a vagabundear por los meandros de la poética de estos autores, por una certeza luminosa como es la imposibilidad de una lectura "estatal" para centrarme en la imposibilidad del sentido único; situarme en un malestar que se capta en el divague por el ritmo de dos fintas de la poesía que implica romper con la tradición de un margen triádico: geográfico, cultural y de las políticas literarias. En decir, ingresar distraídamente por la poética del sabotaje.

Todas las citas que realizaremos de ambos poemas provienen de las siguientes ediciones: Los perros románticos (1998). Ed. Lumen. España. Y Mínimo de mundo visible (2003). Ed. Filodecaballos. México. 


\section{Bolaño vagabundea por los caminos de Santiago}

Roberto Bolaño y Eduardo Espina elijen epígrafes para sus obras que señalan cierta tradición de lectura común como la presencia de Jorge Luis Borges y Sor Juana Inés de la Cruz. También eluden y desactivan las dedicatorias en numerosos textos de sus autorías; el trucaje y la broma de la dedicatoria de Espina que expresa: "Este libro no está dedicado" y en el epígrafe de Mínimo de mundo visible que cita a Sor Juana:

"de manera que aquellas cosas que no se pueden decir, es menester decir siquiera que no se pueden decir"

encuentran su correlato en la poética boloneana; en Tres la voz de Alceo de Metilene expresa:

"Si vas a decir lo que quieres

también vas a oír lo que no quieres"

Ambos intertextos evidencian un zanja entre el decir y no decir, una frontera del deber decir o callar, entre oír/leer o su contrario ${ }^{2}$.Y este matiz es altamente significativo porque se articula con las poéticas de ambos autores en lo referente a cuáles son los caminos para eludir el silencio del monolingüismo.

Tampoco es arbitrario señalar la exterioridad o el borde del canon nacional si pensamos que la consagración del primero proviene de España hacia nuestro continente cuando a fines de la década del noventa obtiene el premio consagratorio Rómulo Gallegos. No olvidemos que el lugar de residencia de Espina es Texas, es decir, en borde de América Latina. Ambos autores anudan sus poéticas a la tradición vanguardista, surrealista y neobarroca tanto europea como americana pero el diálogo con el pasado parece traerla a una dimensión temporal única donde conviven todos los tiempos en uno. En este sentido, y salvadas las cercanías pretendo bordar dos poemas: "El burro" y "Gas de los matrimonios", textos que podemos leerlos si se desea al unísono, invocando la posibilidad que brinda toda lectura "impropia" 3 .

2 Ives Bonnefoy en su texto Lo improbable (1998) y a propósito de la obra de Caravaggio señala esta problemática al referirse a cómo algunos críticos de arte (como Bernard Berenson) carecen de la posibilidad de ver los matices barrocos del pintor. Para una mayor precisión recomiendo la lectura de "Dos libros sobre Caravaggio". Págs.131135.

3 Sostengo que hay ciertos textos críticos situados más allá de la moda. Así, el entrecomillado es un homenaje a Nicolás Rosa y su texto La lengua del ausente (1998). 
En esta dirección, me pregunto por qué la poesía de Bolaño es escasamente trabajada académicamente. El corpus crítico consultado como la compilación de Patricia Espinosa Territorios en fuga (2003) coloca el acento en lecturas dedicadas al estudio del género policial, a la presencia del posmodernismo o bien potencian los rasgos generales de su poesía. Bolaño es poeta de cuño rupturista, y esta observación se hace visible ya desde sus primeros relatos y novelas; allí está alojado su primer gesto vanguardista que se intensifica en toda su producción en un homenaje a la literatura argentina a través de Jorge Luis Borges, Macedonio Fernández, Roberto Artl y Julio Cortázar.

En el poema elegido la tradición está en la fuerte presencia de imágenes borgeanas ( huella , más allá del barroco, registrable también en Espina). Sin embargo, la misma se combina también con una fuerte deconstrucción de la vanguardia surrealista y futurista, mirada con el particular ojo de Bolaño. Ese desmontaje se traduce en el paisaje del norte mexicano y hace de la ciudad y del desierto un espacio infinito que es el punto de partida para numerosos textos-registrable desde Los detectives salvajes a 2666-. Hacia el final del Primer Manifiesto Infrarrealista de 1976 Bolaño expresaba: "Hacer aparecer las nuevas sensaciones-Subvertir la cotidianeidad. O.K.

\section{DÉJENLO TODO, NUEVAMENTE LÁNCENSE A LOS CAMINOS"}

Así, creo que "El burro" constituye una muestra y una invitación de nuestro autor a deambular por ciertos registros estéticos del desierto y el norte. La mejor producción boloneana se teje en un texto de a dos: Belano y Lima, Bolaño y su partenaire, Mario Santiago. Poeta mexicano o, mejor decir, poetas mexicanos. Santiago condujo a Bolaño por los meandros de una poesía mexicana-otra, underground que encuentra en Los detectives salvajes quizá el mejor y más profundo homenaje. Santiago y Bolaño subvierten el origen "estatal" de la poesía, es decir, en toda la obra de nuestro autor Chile emerge como espacio literario y no como espacio de nacionalismos o de las Ilamadas literaturas nacionales. Su poesía es más que esa delimitación territorial, foco de sarcasmo en numerosos escritos boloneanos; Chile es un espacio de múltiples direcciones tanto como sucede en la poética del uruguayo Eduardo Espina.

El viscerrealismo que se codifica en los detectives Belano y Lima, que deambulan en su obra, emula al movimiento poético que en la década del setenta cultivaron Bolaño y Mario Santiago denominado infrarrealismo del que deriva el manifiesto homónimo de 1976. Pero aquel es más que la incursión por la vanguardia; infrarrealismo y viscerrealismo son simples nomenclaturas si no podemos aceptar la invitación de nuestro a 
autor a cruzarnos de senderos, cambiar la dirección única y divagar por meandros, callejones de una poesía donde el relato y la metáfora son pares necesarios porque permiten huir de la nomenclatura canónica de los géneros. Nos permite incursionar por los sueños pesadillescos de un yo poético que si bien recuerda a las vanguardias históricas no se solaza en la repetición; en su homenaje a la formación poética peruana Hora Zero expresa: "Mientras cualquier chavo sueñe y le cuente sus sueños a una chava habrá vanguardia en la nueva poesía" (Bolaño: 1976). Esta declaración implica una poesía donde el sueño que se instala en la libertad del verso como en el caso de "El burro", posee una particular importancia: no sólo obedece a su programa estético sino también que aquel permite al lector ingresar a mundos delirantes para desde allí sabotear lo real; ingresar a la ciudad y al desierto para mostrar que ambos tal como se concibe en el registro realista son una falla. Se necesita del delirio para fundar literariamente un desierto, una ciudad; y también es necesario otro yo, otros "yo" líricos, cercanos a la s calaveras, a imágenes de imágenes fantasmales para pintar lo que se dibuja por dentro. Sin duda, la poesía de Bolaño es una escritura y una lectura tan incómoda como la de Espina, ambas sueñan borgeanamente la relación poesía-tradición de la ruptura.

¿Qué es el norte en la poesía de Bolaño?, ¿en qué cartografía podemos ubicarnos para llegar al norte?. En Nord Sud de Vicente Huidobro se encuentra la vanguardia chilena escrita en francés y con pretensiones de quedar adherida a esta filiación si pensamos en la revista de Paul Reverdi. También Nicanor Parra recuperó sarcásticamente los puntos cardinales que el recuerdo de Bolaño recupera en sus escritos acerca del exilio ${ }^{4}$. Pero el Norte tampoco tiene el vestigio realista de un número bien abundante de autores que observan ese espacio a través del juego utopía-distopía donde la producción chicana, mexicana y chilena pareciera brindar un buen ejemplo: Fernando Alegría (La rebelión de los placeres); José Donoso (Donde van a morir los elefantes), Gloria Anzaldúa (Borderland/La Frontera)....El Norte de Bolaño es un espacio- tiempo alucinado, es un lugar-otro si nos ubicamos en la tradición y queremos observar cómo funciona el injerto... Texas no es Texas, el desierto no lo es, los poetas mendicantes tampoco porque se hacen a partir de la escritura mientras los recuerdan Belano y Santiago, Lima y Bolaño, Bolaño y Santiago... El yo lírico es lírico elegíaco, una imagen doliente de los que no están y que el sueño recupera, un poeta-burro, una realidad infra, una poética infrarrealista, espejean sin tocar el fondo porque éste es inasible. De igual modo, el poema parece re escribir el "yo" en una tradición que rompe se desintegra en la dimensión onírica, un "yo" hecho de claroscuro: yo-

Me refiero a la serie de escritos reunidos bajo el título Entre paréntesis (2005) y especialmente al capítulo "Literatura y exilio". Págs. 40-46. 
sueño, yo-Santiago; Aquiles que busca en sueños a su amigo Patroclo para recuperar lo perdido:

"Y a veces sueño que Mario Santiago

Viene a buscarme, o es un poeta sin rostro,

Una cabeza sin ojos, ni boca, ni nariz, (...)" (Bolaño: 11)

Una bi-dimensión con pretensiones de espejo que se retuerce en cada pliegue del poema parece instituir un modo de hacer poesía y narrativa al unísono y asordinadamente. En yo del "El burro" es también un nosotros y un legado a "los hijos", un situarse en el desierto de la nada para señalar el linaje y la herencia, lo que vendrá ${ }^{~ e n ~ n u e s t r a ~ p o e s i ́ a: ~}$

"En medio de la noche, a un lado de la carretera, Como nuestros hijos queridos y abandonados, Criados solos en estos desiertos calcáreos" (Bolaño: 12).

\section{El poeta burro}

Una de las particularidades de la poesía de Bolaño señalada por la crítica (Alcides Jofré, José Promis, entre otros) a partir de Los perros románticos es la relación poeta-perro en tanto que imagen del poeta vagabundo. Sin embargo, la representación del sujeto es indisociable de la ciudad. Ésta puede ser México DF, Texas o cualquier ciudad europea (ya consigné anteriormente: Texas no es Texas, México no es México, etc), y en el caso de nuestro poema, la díada poeta-burro es inseparable del motivo del viaje. Versión sonambulesca del desplazamiento por el erial mexicano ya sea urbano o desértico, el recorrido parece intimar con una risa al moderno auto para reemplazarlo por la moto. La moto y el yo en medio del desierto en "El burro" potencian la complejidad de la imagen del poeta héroe, y esa heroicidad posee, como ya adelanté, un sentido colectivo que se mediatiza a través de la forma pronominal posesiva y personal: "nuestro": nuestra poesía, nuestra moto, nuestro anhelo, nos dicen adiós, nosotros mismos, etc. El viaje muestra la modernidad-otra, es decir, la huida implica el escape de la ciudad-megalópolis y una búsqueda que estalla en las vísceras de nuestra desigual modernidad latinoamericana. Expresa el yo poético:

"Salimos de la Ciudad de México que es la prolongación

De tantos sueños, la materialización de tantas

Pesadillas, y remontamos los estados (...)" (Bolaño: 12)

5 Aspecto que junto a la institución literaria ha sido parodiada hasta el sarcasmo en numerosos capítulos de La novela nazi en América (1996). 
La moto alude a la juventud perdida y recuperada en el sueño y/o en la palabra poética; moto-burro y viaje canalizan la visión de la pobreza camino al norte al mismo tiempo que constituye la materia misma de la poesía; de allí que el viaje es un paseo hacia una meta distópica:

"Por los caminos del norte, la cabeza y yo

Extraños tripulantes embarcados en una ruta

Miserable, caminos borrados por el polvo y la lluvia,

Tierra de moscas y lagartijas, matorrales resecos

$Y$ ventiscas de arena, el único teatro concebible

Para nuestra poesía" (Bolaño: 12).

La apuesta hacia la vanguardia histórica implica la renovación de las formas poéticas y se codifica, entre otros aspectos, a partir de un trabajo minucioso con el motivo literario del sueño ${ }^{6}$. Considero que éste se sitúa en una dimensión más profunda que el legado surrealista; es un canal que muestra la inadecuación del yo larvado con respecto a la realia: aquel sitúa a los protagonistas más cerca de la huida y la aventura; el sueño intensifica en el yo "nuestra esperanza, nuestro valor". La dimensión onírica es el espacio que le permite recuperar esos valores caros a los infrarrealistas. Asimismo, el texto trasunta una lectura minuciosa de Jorge Luis Borges en la presencia de cierta adjetivación: "sueño innombrable e inútil", "pequeños desafíos inútiles" o en el uso de ciertos sustantivos: sueño, valentía, geometría.

El sueño provoca una con/fusión de planos como lo concibe también la tradición maya quiché; ; en el tenso diálogo con la tradición surge la búsqueda del Norte. Polvo, desierto y nada permiten observar en qué estado se encuentra el legado poético en América para "nuestros pobres hijos". "Yo", Santiago y la genealogía literaria se conjugan en un enigma a develar, en un enigma de (poe)sía, tal como puede observarse en Los detectives salvajes cuando Belano y Lima le responder a Amadeo Salvatierra acerca del poema de Cesárea Tinajero: " El poema es una broma, dijeron ellos, es muy fácil de entender, Amadeo (...) (Bolaño:400) ${ }^{8}$.

Los cruces e hibridaciones de los vasos comunicantes entre textos y textos boloneanos potencian la "desolación de la poesía" (Bolaño: 401)

6 A Bolaño, lector pantagruélico, y más allá de la huella surrealista (que puede leerse también en el relato "Último atardeceres en la tierra" de Putas asesinas /2001), con seguridad no le era ajena la tradición griega tanto como inglesa (Shakespeare) o española (Calderón de la Barca).

7 Estas relaciones que implica una determinada asunción de la tradición cultural revela las tensiones antropofágicas de los autores que practicaron el surrealismo tal como Miguel Ángel Asturias y su obra canónica El señor presidente (1946).

$8 \quad$ No olvidemos que en la novela citada los personajes emprenden un viaje al mítico norte boloneano en busca de Cesárea Tinajero. 
plasmada en la recurrencia del adjetivo "inútil" y nos enfrenta a un hueco de significación, un no dicho expresamente, un desierto de la palabra, un re/pliegue que implica la carencia de los grandes temas ${ }^{9}$ en fin de siglo, común a la literatura utópica revolucionaria que ocupaba en campo intelectual de los setenta en América Latina. "El burro" es un homenaje a los infrarrealistas pero además señala en "los desiertos calcáreos" un vacío de la palabra.

La relación yo/nosotros- viaje/aventura, anticipada en el Manifiesto Infrarrealista de 1976 encuentra plena vigencia en la poética de Bolaño de fin de siglo y del nuevo milenio. Expresa en el citado texto:"Formas de vida y formas de muerte se pasean cotidianamente por la retina. Su choque constante da vida a las formas infrarrealista. EL OJO DE LA TRANSICIÓN" (Bolaño, 1976: 4). El viaje hacia el norte es llevado a cabo por Belano, Lima, las calaveras en viaje y propician una aventura otra que implica la vida-muerte, sueño-vigilia, lucidez-alucinación, tradiciónruptura, pasado-presente. La imagen del burro tanto como la del yo son inestables ya que por momentos ambos se identifican en su plenitud o por vía de la metonimia-moto. Es importante destacar que las imágenes de nocturnidad realizan los deseos de la realidad otra:

"Y mientras el sueño me transporta

De un continente a otro

A través de una ducha de estrellas (...)" (Bolaño:13)

La velocidad del texto se conjuga a través del juego imaginal inerciadinamismo, como dos estados simultáneos originados en el desplazamiento. Este juego implica un desbocarse hacia la muerte alucinada y en consecuencia la herencia para los hijos literarios es un legado donde la nada, el calor, la alucinación y la presencia del poeta héroe se abisman hacia un lugar límite. Esta experiencia puesta en el juego detenciónmovimiento, inercia dinamismo, desesperanza-esperanza a través de la moto rompe los límites de las díadas arriba mencionadas y potencian fundamentalmente en el espacio fronterizo del "límite-abismo", el límite-margen:

"Y a veces creo ver una moto negra

Como un burro negro alejándose por los caminos

De tierra de Zacatecas y Coahuila, en los límites

Del sueño, y sin alcanzar a comprender

Su sentido (...)" (Bolaño: 12-13)

9 Tema igualmente recurrente bajo diferentes modulaciones en la poética boloneana; pensemos cómo se codifica esta preocupación a través de algunos sobrevivientes de la cultura pre-golpe como es Abel Romero, policía allendista y posterior perseguidor de Carlos Wieder en Estrella distante (1996). 
Si el yo poético tal como lo concebían los infrarrealistas se lanza a la aventura y se funde en el recuerdo de su partenaire Mario Santiago, el lector como co-partícipe de dicho proceso, se torna igualmente alucinado, condición necesaria para deambular por la poética de Bolaño.

\section{"Gas de los Matrimonios" un haz de Mínimo de mundo visible de Eduardo Espina}

La capacidad aglutinante por vía de la escritura neobarroca de Eduardo Espina conlleva leer el intertexto borgeano de la cita ubicada en el título del libro como haz de un sentido más relacionable con el sabotaje que con la repetición. Así, ningún principio de ordenamiento rígido es plausible de ser desarrollado para un análisis del poema en cuestión. En este sentido, es preciso advertir que, en la vinculación de poéticas tan disímiles como la de Bolaño y Espina, la imbricación de discursos es trabajada de tal modo que la adquisición y metabolización de las tradiciones implican un registro escriturario que muestra a los textos seleccionados como pequeñas joyas facetadas de, repito, un homenaje disolvente. Un tipo de alianza con la tradición cultural en sentido más vasto que la específicamente literaria.

"Gas de los matrimonios", tema que el sencillismo argentino pudo haber explotado hasta el hartazgo, se recuesta sobre ciertos andamiajes de particular importancia. No olvidemos que Ruinas circulares (1944) de Borges es considerado uno de los relatos fantásticos del canon argentino y ejercicio vanguardista por excelencia pero la finta extraída por Espina no imita, no repite sino que la transformación por vía del injerto está puesta al servicio del tema que conlleva, en el poema seleccionado, cierto tipo de contrato.

La cópula matrimonial implica la firma de una alianza simbólica entre dos; la cotidianidad del acto, la falta de brillo barroco, el acuerdo, una ruina circular potenciado en el anillo, dimensión del contrato y la costumbre encuentra en lo momentáneo su reverso sobre el que se sustenta el poema. Mientras se dice el contrato matrimonial se lo desmonta a través de la amenaza, "gas"; en síntesis: el lenguaje muestra el desbarajuste de lo cotidiano, una disrupción de la costumbre que el lenguaje capta a través de la construcción escénica de lo momentáneo: "Ellos allí, una moneda y el momento" (Espina: 17); en esta dirección es importante la mirada del yo que otea por la escena erótica donde se instituye el contrato y la ruptura del mismo: 
"Ellos allí, (...)

Sabios se los vio avistando el tándem" (Espina: 17)

Los textos de Bolaño y el Espina alteran una doble escena: la del decir y lo que se dice, esto es, proceder, a través del cuño vanguardista y barroco, por ciertos ripios poéticos donde lo mínimo de mundo visible implica no sólo lo que ve-dimensión del tema- sino cómo ve el ojo y en consecuencia la implicancia sine qua non de la actividad lectorial. Asimismo, entre Espina y Bolaño es posible observar cómo adulteran la tradición de la costumbre: los hijos de Bolaño son los matrimonios de Espina; así la genealogía se instaura para pulverizarla.

El yo pareciera portar con su ojo el chiste de ver y deconstruir al mismo tiempo. El humor que surge de esta doble dimensión dialoga con la cita de Hopper; la operación permite disolver la melancolía proveniente no sólo de la dimensión temática de pintura realista del citado artista sino que el trabajo con el lenguaje del poema va tejiendo un texto-otro hecho de un diálogo con la tradición que la cita nos permite captar:

"Ante lo irrepetible se cumplen sin plan

En un cuadro de Hopper: la verdad los vería mirando por las ventanas y ellos

ayunaban lo mismo que el nacimiento." (Espina: 18)

Si el epígrafe de Juana de México parece direccionar la lectura hacia la hiancia, hacia el hueco silencioso del "callar", el tema del poema de Espina indica un trabajo escriturario donde el título anticipa el tema mientras que la escritura lo desmonta. La joya neobarroca deviene en este sentido en una musicalidad asordinada, un ritornelo, un agenciamiento del mundo cotidiano que se desbarata en los juegos rítmicos del lenguaje y en la cópula; el entrecruce de planos potencia el ritmo erótico que se monta sobre un sutil equilibrio donde el límite se traza entre los términos concensuados de la calle y la ruptura:

"Dale que dale y al cabo de una bujías..." (Espina:17 )

En esta dirección es posible señalar la bizarría de la lengua que combina las imágenes del goce con otras de cuño borgeano:

"tal cual la entendían, cuántas preguntas

a pesar del espejo y las luces a lo largo

que pocas ganas si quedaran ordeñados" (Espina: 37)

El espesor semántico de "ordeñados" religa la imagen de la distensión erótica con la actividad ganaderil. En este sentido, el procedimiento se 
erige en una sutil continuidad de la tradición perlongheriana del barroco rioplatense.

En el espacio límite el lenguaje de los cuerpos por vía de la metonimia dialogan con el cuadro del artista americano:

"En la era de la novia rota con que eran

Mundo de músculo y mirada remecida" (Espina: 17)

En este sentido, es interesante observar el juego aglutinante del lenguaje que arrastra en un tenso equilibrio entre la lengua popular y la tradición erudita como por ejemplo los ya citados pasajes de raigambre borgeana: "lo irrepetible", "luces a lo largo" o bien el motivo del espejo. Asimismo, el juego sonoro que se establece entre el sustantivo y el verbo "era/eran" introduce de modo paulatino no sólo la bizarría de la mezcla rabelesiana en la representación de la puja que arremete con la institución matrimonial ${ }^{10}$, sino también una política de resistencia del lenguaje neobarroco. En esta dirección, es posible señalar una dimensión de la inercia:

"Un logro complacido por el anillo los obligaba a la unión y la perseverancia de estar sentados (...)" (Espina:37)

frente a la arritmia del eros, puesta en el significante "gas" o bien en la intensidad que porta "ordeñados". Este juego se intensifica al final del poema, donde la voz de la plaza pública interviene en el texto señalando la caducidad del instante de los amantes: "Cualquiera diría, hieren desconocidos" (Espina: 18).

El ver de la voz anónima y coloquial puesta en "cualquiera diría" (que cumple una función similar al tratamiento de "dale que dale"), o viceversa, la voz que ve, "hieren desconocidos", es un rasgo que se sostiene en todo Mínimo de mundo visible. Lo importante de destacar es la tensión de tradiciones y registros de lengua si pensamos que el primer enunciado citado, perteneciente a la dimensión de lo cotidiano, converge en la imagen "hieren desconocidos", perfil que se carga de cierto registro erudito. En esta dirección, la polifonía callejera se potencia a través del ojo que ve y se interroga "¿Será posible?" que al mismo tiempo pulveriza el mito adánico del pecado original:

¿Será posible? Un trozo de padrinazgo para extraer al entrometido por detrás, un árbol más veces a la unión original" (Espina:37)

10 No menos interesante es observar el trabajo con la tradición de la poesía de Sor Juana en otros textos de MMV como puede ser "Secreto de estado". 
Esta operación implica un gesto disruptor frente a la tradición romántica del yo lírico ya que "cualquiera" y la forma interrogativa intensifica la desubjetivación, una revulsión de la fijeza de la primera persona, dominio enunciativo, por ejemplo, del poema de Bolaño.

El desdén del dato real, caro a la poesía neobarroca, elude la descripción con el fin de dejar paso a la intensidad de la palabra. Así, el significante "pelo" o el injerto de formas refranescas como "moros en la costa" canaliza un modo otro de arremeter contra la institución literaria e implanta pactos de lectura, alejados de las imposiciones de las leyes del mercado.

En este sentido, son importantes las observaciones de Héctor Libertella con respecto al surgimiento del neobarroco de Lezama Lima y su relación con el mercado literario como formador de gusto por ciertas lecturas tranquilizadoras; expresa el crítico y poeta argentino: "Este viaje de estilo, visto ahora a la luz de sus vicisitudes de consumo y rechazo, habla directamente de una costumbre casi antropofágica en el lector: consumir persona, escritor; consumir código (...). Pero junto a ése hay otro viaje del estilo: el de los productos, cómo llamarlos: ¿desviados?, que estuvieron mucho tiempo esperando otra madurez de lectura: el momento también difícil del lector, el del cambio o revisión de sus propias maneras de leer. El jeroglífico, la oscuridad y el enigma que empiezan a articularse con ese lector, para sacarlo de quicio, son las señales de que esta obra puede ser leída, ahora, como una contribución social. Ante todo, porque obliga a cambiar de costumbres de lectura que un mercado propició. Pero también, porque obliga al lector a reconocerse en un nuevo espacio económico y en otro tipo de intercambios más complejos que antes le estaban vedados-que la democracia feliz le negaba." (Libertella: 59).

\section{Conclusión}

Creo que la vigencia de la poesía de Roberto Bolaño y Eduardo Espina, cuyos procedimientos abrevan en fuentes culturales diversas, implica la existencia excéntrica de poéticas que se ubican en el límite del buen decir y la risa de fondo pero al mismo tiempo muestran la escasa circulación por el discurso académico de América del Sur, propenso a la tranquilidad del canon. Esta problemática, en el caso de Espina, se intensifica por la ausencia en las librerías argentinas de su producción poética. Desde esta perspectiva se puede explicar por qué la poesía, ese segmento de la producción boloneana, es escasamente trabajado a igual que la obra del poeta uruguayo. Léase la aparición de la Universidad desconocida (2007) sólo como un gesto de las políticas del mercado editorial en lo referente a "Bolaño vende". 
Leer las dos fintas de ambos fue introducirme por una creación donde el sueño y el juego implica otro contrato de lectura: su goce donde, sin ningún riesgo, habita, parafraseando a Libertella, la dimensión social de la creación literaria, donde habita aquella carta robada de Poe, aludida por Bonnefoy: el enigma de la (poe)sía.

\section{Bibliografía}

Bajtín, Mijaíl (1994).

Bolaño, Roberto (1976). (1998). (2000). (2005).

Bonnefoy, Ives (1998). (2002).

Espina, Eduardo (2003).

Espinosa, Patricia.

Libertella, Héctor (1993).

Perlongher, Néstor (1997). Rosa, Nicolás (1997).
La cultura popular en la Edad Media y en el Renacimiento. El contexto de Francois Rabelais. Ed. Alianza. España.

"La nueva poesía latinoamericana". Revista Plural. México.

Los perros románticos. Ed. Lumen. España.

Tres. Ed. El acantilado. España.

Entre paréntesis. Ed. Anagrama. España.

Lo improbable. Ed. Alción. Córdoba. Rep. Arg. Tr. Silvio Mattoni.

Sobre el origen y el sentido. Ed. Alción. Córdoba. Rep. Argentina. Tr. Silvio Mattoni.

Mínimo de mundo visible. Ed. Filodecaballo. México.

Territorios en fuga. Estudios críticos sobre la obra de Roberto Bolaño. Ed. Frasis. Santiago de Chile. FECHA

Las sagradas escrituras. Ed. Sudamericana. Buenos Aires.

Prosa plebeya. Ed. Colihue. Buenos Aires. La lengua del ausente. Ed. Biblos. Buenos Aires. 